\title{
Konstruksi Model Matematika Paralayang dengan Target Pendaratan
}

\author{
Firdo Alhamda P, Hariyanto, dan Iis Herisman \\ Departemen Matematika, Fakultas MKSD, Institut Teknologi Sepuluh Nopember (ITS) \\ e-mail: hariyanto@matematika.its.ac.id
}

\begin{abstract}
Abstrak-Konstruksi model matematika dari pergerakan penerjun dibagi dalam dua pengamatan, yaitu ketika penerjun belum membuka parasut dan setelah penerjun membuka parasut. Pengontrolan dalam penelitian ini dikhususkan saat penerjun sudah membuka parasut hingga mendarat. Untuk mengendalikan parasut, dapat dilakukan dengan cara menggerakkan tali kemudi yang berpusat dibelakang parasut. Dengan menarik tali kemudi kanan ke bawah, maka parasut bergerak ke kanan. Dan jika menarik tali kemudi kiri ke bawah, maka parasut bergerak ke kiri. Untuk mendapatkan model dari paralayang, digunakan metode derivatif dari penurunan Hukum Newton. Dari model yang didapatkan kemudian dikontrol dengan menggunakan PID controller agar penerjun mampu mendarat pada target pendaratan yang diharapkan dengan mengikuti dari setpoint atau lintasan yang telah dibuat sebelumnya
\end{abstract}

Kata Kunci-Parasut, PID, Pendaratan.

\section{PENDAHULUAN}

$\mathrm{P}$ ARALAYANG merupakan salah satu olahraga yang paling ekstrim. yang juga bertujuan untuk mendistribusikan tentara di tempat terpencil. Kanopi pada parasut, terbagi dua yaitu ada yang berbentuk lingkaran dan ada yang berbentuk persegi panjang. Untuk kegiatan olahraga dengan parasut yang berbentuk persegi panjang, nama olahraga nya biasa disebut paralayang. Sekarang ini, olahraga paralayang yang khas dipakai adalah pada ketinggian 4000 meter dengan membuka parasut pada ketinggi [1].

Parasut merupakan alat yang digunakan untuk memperlambat gerakan suatu objek di udara dengan menciptakan hambatan udara (drag). Drag di dapat dari luas permukaan parasut, jadi semakin luas parasut maka semakin besar beban yang bisa dibawanya. Ketika penerjun melompat dari pesawat, hanya ada satu gaya yang bekerja padanya, yaitu gaya gravitasi (berat penerjun) dalam kasus ini penerjun melakukan gerak jatuh bebas. Pada saat penerjun mulai turun, gesekan udara ke atas melawan gerakannya, gesekan ini mulai bertambah sehingga gaya kebawah menjadi berkurang. [meade]

Pada Gambar 1, merupakan tentang beberapa bagian yang perlu diketahui agar semakin lebih mengenal dengan parasut paralayang. Bagian-bagian yang harus dipahami antara lain:

[2]

1. Wing

2. Lines and risers

3. Harness

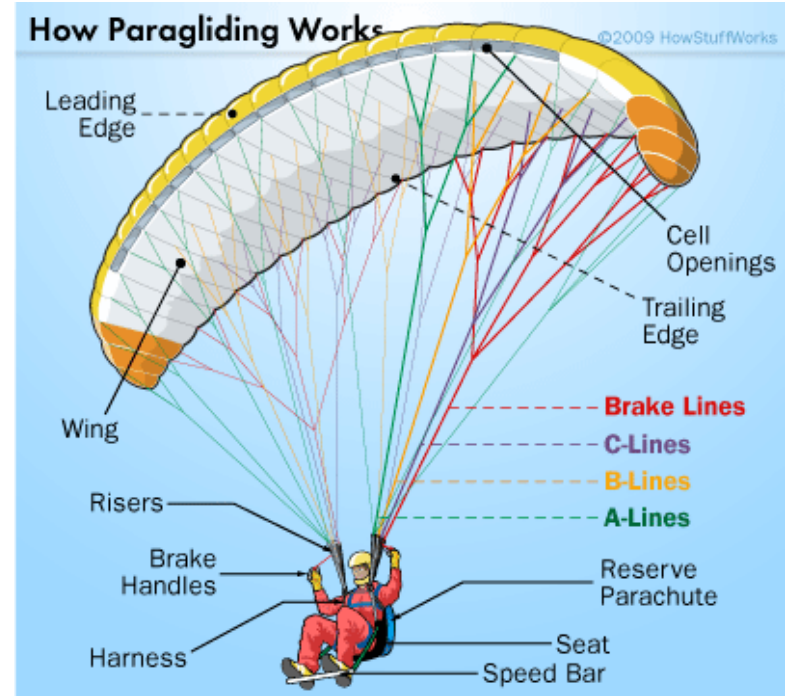

Gambar 1. Bagian-bagian parasut.

\section{Speed bar \\ 5. Reserve Parachute \\ 6. Helmet.}

Tali menempel pada area yang berbeda dari sisi bawah sayap. Di bawah kanopi, menggantung beberapa tali yang tersusun sekitar empat atau lima baris. Baris terakhir berfungsi sebagai pusat kemudi seperti rem, atau tali kontrol, menempel pada trailing edge. Tali-tali tersebut diikat di kedua sisi penerjun. Sekumpulan tali dikelompokkan disebut risers dan risers tesebut yang membuat penerjun dapat menggantung di bawah kanopi. Penerjun bisa menggunakan tali kontrol untuk mengontrol paralayang. Memanipulasi tali dapat mengubah arah atau kecepatan parasut saat terbang. Risers melekat pada harness. Harness adalah seperangkat tas yang dibawa oleh penerjun yang sekaligus juga merupakan tempat dimana penerjun duduk selama menerjun. Kegunaannya untuk mengunci rapat supaya penerjun aman [2].

Parasut dihubungkan pada penerjun dengan tali dan tali tersebut didistribusikan ke seluruh parasut seperti pada gambar 2. Ini adalah tali yang terdapat di belakang parasut dan bergabung bersama-sama menjadi satu tali di setiap sisi parasut yang memungkinkan untuk menerbangkannya. Tali tersebut dinamakan dengan tali kemudi. Dan tali-tali yang telah menyatu tersebut digunakan sebagai pegangan yang dapat dipegang untuk mengendalikan parasut yang dinamakan dengan togel. 


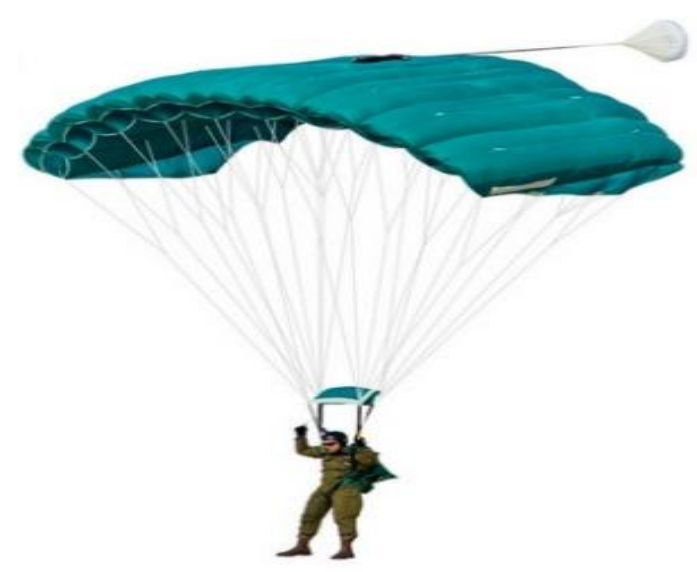

Gambar 2 Parasut dan pusat control.

Dengan menarik togel kanan ke bawah, maka parasut akan bergerak mengarah ke kanan. Dan jika menarik togel kiri ke bawah, maka parasut akan bergerak mengarah ke kiri. Fungsi lain yang sangat penting dari togel adalah sebagai rem parasut. Ini berarti menarik ke bawah pada kedua matik sekaligus, menarik seluruh ujung belakang parasut ke bawah, dan ini memperlambat penurunan parasut sehingga dapat membuat pendaratan.

\section{URAIAN PENELITIAN}

\section{A. Study Literatur}

Pada tahap ini akan dilakukan pencarian referensi yang menunjang penelitian ini serta mempelajari lebih dalam tentang hal - hal yang berpengaruh dalam pembuatan model terjun payung.

\section{B. Pembentukan Model}

Dalam pembentukan model ada beberapa tahapan diantaranya asumsi posisi penerjun setelah melompat dari pesawat, analisa gerak penerjun selama di udara dan penurunan rumus kecepatan dan posisi terhadap waktu serta menganalisa pergerakan penerjun mulai dari gerak jatuh bebas dari pesawat sampai pada posisi siap membuka parasut.

\section{Penyelesaian Numerik}

Dalam tahap ini akan dibuat model persamaan penerjun payung dengan pendekatan Hukum Newton, mulai dari penerjun melakukan terjun bebas dari pesawat, sampai penerjun pada posisi siap membuka parasut.

\section{Simulai Numerik}

Dalam simulasi numerik akan digunakan MATLAB sebagai simulator. Setelah didapat model persamaan dari terjun payung, selanjutnya akan dibuat algoritma dari persamaan tersebut untuk disimulasikan.

\section{E. Kesimpulan}

Dalam tahap ini akan diambil kesimpulan dari hasil simulasi numerik yang telah dilakukan.

\section{F. Pembuatan Laporan Studi}

Dalam tahap ini akan dilakukan penulisan dari semua hasil penelitian yang sudah dilakukan.

\section{PETUNJUK TAMBAHAN}

\section{A. Konstruksi Model Matematika Terjun Payung}

Konstruksi model matematika pada penerjun payung yang akan dibangun adalah saat mulai membuka parasut hingga mendarat pada target. Pada Studi ini diasumsikan penerjun payung melakukan gerak jatuh bebas dari pesawat dan langsung membuat posisi membentangkan badannya kebawah sehingga tercipta hambatan udara yang besar.

Diketahui hukum Newton 2 adalah sebagai berikut :

$$
\begin{aligned}
& \text { Dengan : } \\
& \Sigma F=\text { resultan gaya } \\
& \mathrm{m}=\text { massa } \\
& \mathrm{a}=\text { percepatan }
\end{aligned}
$$

Seperti yang sudah disebutkan tentang dasar persamaan gerak, persamaan, dapat dijabarkan sebagai berikut

$$
\begin{aligned}
& \Sigma F=m a \\
& m g-\frac{\rho A C_{d} V^{2}}{2}=m a \\
& \dot{v}=\frac{2 m g-\rho A C_{d} V^{2}}{2 m}=g-\frac{\rho A C_{d} V^{2}}{2 m}
\end{aligned}
$$

Untuk mencari komponen vertikal dapat dimissalkan dengan

$\dot{y}=v$

Sehingga, model matematika terjun payungnya yaitu

$\dot{\mathrm{y}}=\mathrm{v}$

$\dot{v}=\frac{2 m g-\rho A C_{d} V^{2}}{2 m}=g-\frac{\rho A C_{d} v^{2}}{2 m}$

Sehingga diperoleh persamaan ruang keadaan sebagai berikut :

$$
\left[\begin{array}{l}
\dot{y} \\
\dot{v}
\end{array}\right]=\left[\begin{array}{cc}
0 & 1 \\
0 & -\frac{\rho A C_{d^{D}}}{2 m}
\end{array}\right]\left[\begin{array}{l}
y \\
v
\end{array}\right]+\left[\begin{array}{l}
0 \\
g
\end{array}\right]
$$

Karena matriks A tidak linier, maka harus dilinierisasi dengan menggunakan matriks Jacobi sebagai berikut

$$
l=\left[\begin{array}{ll}
\frac{\partial \dot{x}}{\partial y} & \frac{\partial \dot{y}}{\partial v} \\
\frac{\partial \dot{v}}{\partial y} & \frac{\partial \dot{v}}{\partial v}
\end{array}\right]
$$

Diketahui

$$
\begin{aligned}
& \dot{y}=v \\
& \dot{v}=-\frac{\rho A C_{d V^{2}}}{2 m}
\end{aligned}
$$

Sehingga

$$
\begin{aligned}
& \frac{\partial \dot{y}}{\partial y}=0 \\
& \frac{\partial \dot{y}}{\partial v}=1
\end{aligned}
$$




$$
\begin{aligned}
& \frac{\partial \vec{v}}{\partial y}=0 \\
& \frac{\partial \dot{v}}{\partial v}=-\frac{\rho A C_{d} v}{m}
\end{aligned}
$$

Sehingga diperoleh persamaan ruang keadaan sebagai berikut :

$\left[\begin{array}{l}\dot{y} \\ \dot{v}\end{array}\right]=\left[\begin{array}{cc}0 & 1 \\ 0 & -\frac{\rho A C_{d}}{m}\end{array}\right]\left[\begin{array}{l}y \\ v\end{array}\right]+\left[\begin{array}{l}0 \\ g\end{array}\right]$

Dengan keluaran sistem

$y=\left[\begin{array}{ll}1 & 0 \\ 0 & 1\end{array}\right] \mathrm{x}$

\section{B. Perancangan Desain PID}

Sebelum merancang desain kendali terlebih dahulu merancang plant yang akan dikendalikan yaitu dengan menggunakan persamaan keadaan Diagram blok persamaan keadaan parasut

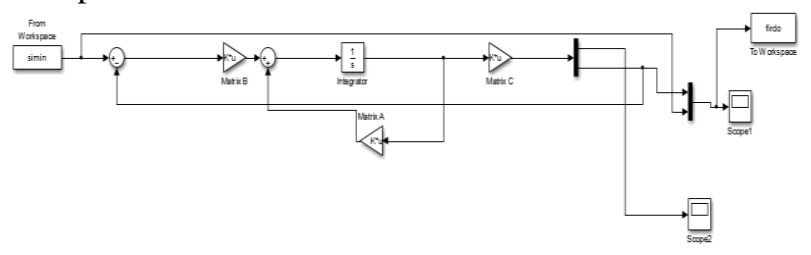

Gambar 4. Plant parasut.

PID merupakan sebuah sistem kendali yang mempunya tiga komponen utama yaitu Proporsional, Integrator, Derivatif dengan tiga gain $K_{p}, K_{\mathrm{f}}, K_{d x}$. Untuk merancang system kendali PID terlebih dahulu menentukan gain, yang sesuai pada persamaan:

$$
u(t)=K_{p} e(t)+K_{\mathrm{i}} \int e(t) d t+K_{d} \frac{d e(t)}{d t}
$$

Dengan $e(t)$ adalah selisih antara nilai pengukuran dan setpoint.

Perancangan desain kendali PID dengan menggunakan Simulink MATLAB ditunjukkan pada Gambar 5.

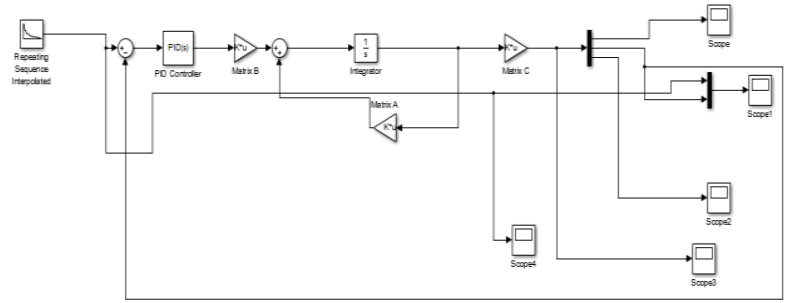

Gambar 5. Desain kendali PID konvensional.

\section{Simulasi dan Analisis}

Saat menerjun, penerjun harus mengikuti lintasan. Untuk itu, perlu tracking lintasan agar penerjun tetap berada di lintasan dan dapat. Hasil plot dari penerjun dengan lintasannya sebagai berikut.

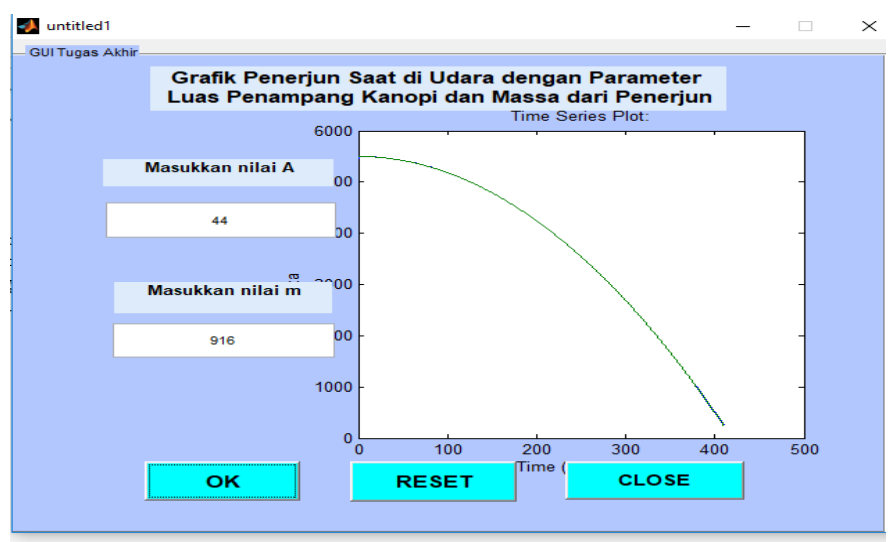

Gambar 6. Simulasi penerjun selama di ketinggian terhadap waktu.

Dari hasil simulasi terlihat bahwa Pada kendali PID penerjun stabil menuju setpoint dari awal ketika penerjun mulai menerjun

\section{KESIMPULAN}

Berdasarkan hasil analisis dan pembahasan pada bab sebelumnya, dapat disimpulkan beberapa hal sebagai berikut:.

Beberapa hal yang penting diperhatikan oleh penulis:

1) Sistem model matematika dari pergerakan penerjun payung adalah sebagai berikut : $\dot{y}=v$

2) $\dot{v}=g-\frac{p A C_{d} D^{2}}{2 m}$

Dari hasil simulasi terlihat bahwa Pada kendali PID penerjun stabil menuju setpoint dari awal ketika penerjun mulai menerjun

\section{DAFTAR PUSTAKA}

A. Asmianto, "Konstruksi Model Matematika Pada Terjun Payung Dengan Akrobat Perubahan Posisi Sebelum Parasut Dibuka," J. Sains dan Seni ITS, vol. 5, no. 2, 2016.

[2] D. B. Meade and A. A. Struthers, "Differential Equations in the New Millennium: the Parachute Problem*." 